\title{
HUBUNGAN RIWAYAT HIPERTENSI DAN PARITAS DENGAN ASFIKSIA NEONATORUM PADA IBU BERSALIN PREEKLAMPSIA BERAT
}

\author{
Dyah Muliawati ${ }^{1}$, Endang Sutisna ${ }^{2}$, Uki Retno ${ }^{3}$ \\ ${ }^{1}$ Sekolah Tinggi Ilmu Kesehatan Madani Yogyakarta \\ ${ }^{2,3}$ Universitas Sebelas Maret Surakarta \\ e-mail: dyah.muliawati@gmail.com
}

\begin{abstract}
ABSTRAK
Asfiksia neonatorum adalah keadaan bayi baru lahir mengalami kegagalan bernafas spontan dan teratur. Asfiksia neonatorum merupakan urutan pertama penyebab kematian di negara berkembang yaitu sebesar $21.1 \%$, salah satu penyebabnya dari faktor ibu yaitu preeklampsia dan eklampsia. Tujuan penelitian untuk menganalisis hubungan riwayat hipertensi dan paritas dengan asfiksia neonatorum pada ibu preeklampsia berat. Subjek penelitian yaitu 40 bayi asfiksia dan 40 tidak asfiksia yang dilahirkan oleh ibu dengan preeklampsia berat. Jenis penelitian kuantitatif, metode observasi analitik, desain case control, dan pendekatan retrospektif dengan studi dokumentasi tahun 2014 di RSUD Panembahan Senopati Bantul. Analisis bivariat dengan uji Chi-Square, dan multivariat dengan uji regresi logistik ganda. Ibu dengan riwayat hipertensi memiliki risiko 11.9 kali lebih besar daripada tanpa riwayat hipertensi $(\mathrm{OR}=11.9 ; \mathrm{CI} 95 \%=1.92-73.79 ; \mathrm{p}=0.008)$. Ibu primipara memiliki risiko untuk melahirkan bayi dengan asfiksia 3.43 kali lebih besar daripada multipara $(\mathrm{OR}=3.43$; CI 95\% $=1.08-10.88 ; \mathrm{p}=0.036)$. Terdapat hubungan yang positif dan secara statistik signifikan antara riwayat hipertensi dan paritas dengan risiko untuk melahirkan bayi dengan asfiksia.
\end{abstract}

Kata Kunci : Hipertensi, Paritas, Asfiksia, Preeklampsia.

\begin{abstract}
Asphyxia neonatorum is a condition when a newborn baby experiencing spontaneous and regular breathing failure. It is the main cause of newborn death in the developing countries with rate of $21.1 \%$, ones of the maternal factors that contribute to a.n are preeclampsia and eclampsia. The purpose of the research is to analyze the relationships of hypertension history and parity with asphyxia neonatorum case on mothers with severe preeclampsia. The subjects are 40 babies with and 40 babies without asphyxia case born by mothers with severe preeclampsia. The research type is quantitative research, analytical observation method, design case-control, and a retrospective approach with study of documentations in the year 2014 in the Provincial Hospital of Panembahan Senopati Bantul. The analysis methods are the bivariat analysis with Chi-Square test, and multivariate analysis with logistic regression test. The mother with a history of hypertension risk 11.9 times greater than without a history of hypertension $(\mathrm{OR}=11.9 ; \mathrm{CI} 95 \%=1.92-73.79 ; \mathrm{p}=$ 0.008). The mother was birthing the risk of primipara babies with asphyxia is 3.43 times greater than that of multipara (OR $=3.43$; CI 95\% $=1.08-10.88 ; \mathrm{p}=0.036)$. There is a positive relationship and statistically significant between hypertension history and parity with the risks of giving birth for babies with asphyxia case.
\end{abstract}

Keywords : Hypertension, Parity, Asphyxia, Preeclampsia.

\section{PENDAHULAN}

Menurut World Health Organization

(WHO), asfiksia neonatorum merupakan urutan pertama penyebab kematian di negara berkembang pada tahun 2007 yaitu sebesar
$21,1 \%$, setelah itu pneumonia dan tetanus neonatorum, masing-masing sebesar $19 \%$ dan 14,1\%. Asfiksia dapat disebabkan oleh beberapa faktor, salah satu faktor penyebabnya 
adalah faktor ibu yaitu preeklampsia, eklampsia, demam selama persalinan, infeksi berat, dan kehamilan lewat waktu (Kemenkes RI, 2010).

Menurut profil Daerah Istimewa Yogyakarta (DIY) tahun 2012, Angka Kematian Ibu (AKI) di DIY sebesar 56 kasus, Angka Kematian Neonatal (AKN) sebesar 241 kasus, dan Angka Kematian Bayi (AKB) sebesar 346 kasus atau sebesar 30/100.000 Kelahiran Hidup (KH). Preeklampsia berat merupakan penyebab kematian ibu terbesar di Kabupaten Bantul DIY yaitu sebesar 5 kasus dan kematian neonatal terbanyak disebabkan oleh Bayi Berat Lahir Rendah (BBLR) dan asfiksia. Di RSUD Panembahan Senopati Bantul pada tahun 2014 terdapat 175 kasus preeklampsia pada ibu bersalin dan 635 kasus asfiksia neonatorum.

Perubahan fisiologis terberat yang terjadi pada neonatus adalah transisi dari sirkulasi janin atau plasenta ke respirasi independen. Hilangnya hubungan plasenta menyebabkan hilangnya dukungan metabolisme seutuhnya, terutama suplai oksigen dan pengeluaran karbondioksida. Stres normal yang terjadi selama persalinan dan kelahiran menyebabkan perubahan pola pertukaran gas plasenta, keseimbangan asam basa darah, dan aktivitas kardiovaskular pada bayi. Faktor-faktor yang mempengaruhi transisi normal ini atau yang meningkatkan asfiksia janin akan mempengaruhi penyesuaian janin terhadap kehidupan ekstrauterin (Wong, 2009).

Asfiksia adalah keadaan bayi baru lahir yang tidak segera menangis, sehingga tidak dapat bernapas spontan maka menyebabkan oksigenasi terganggu ke organ vital yakni otak. Salah satu penyebab asfiksia neonatorum adalah preeklampsia dan eklampsia. Keadaan tersebut dapat menyebabkan aliran oksigen ke janin berkurang yang berakibat terjadi gawat janin yang akan menyebabkan terjadinya asfiksia pada bayi baru lahir (Manuaba, 2010). Sementara itu, menurut penelitian Gilang (2011), Asfiksia neonatorum terjadi ketika bayi tidak cukup menerima oksigen sebelumnya, selama atau setelah kelahiran. Faktor yang menyebabkan asfiksia neonatorum antara lain keadaan ibu, keadaan bayi, plasenta, dan persalinan. Faktor keadaan ibu meliputi hipertensi pada kehamilan (preeklampsia dan eklampsia) sebesar 24\%, perdarahan antepartum (plasenta previa dan solusio plasenta) sebesar 28\%, anemia dan Kekurangan Energi Kronis (KEK) berkisar kurang dari $10 \%$, infeksi berat $(11 \%)$, dan kehamilan lebih bulan (postdate).

Menurut Mansjoer (2007), depresi pernafasan bayi baru lahir dikarenakan faktor kehamilan dan faktor persalinan. Faktor kehamilan dari sebab maternal salah satunya adalah grandemultipara. Menurut beberapa penelitian yang dilakukan menunjukan bahwa faktor-faktor seperti paritas, usia kehamilan, tekanan darah, fungsi hati, dan fungsi ginjal merupakan beberapa penyebab morbiditas kehamilan dengan hipertensi atau preeklampsia. Pada penelitian ini, dari 244 nulipara $188(77.05 \%)$ diantaranya menderita hipertensi dalam kehamilan. Pada ibu hamil dengan preeklampsia $2-8 \%$ diantaranya mengalami komplikasi (Koopmans, et al, 2011).

\section{METODE}

penelitian kuantitatif, dengan metode penelitian observasi analitik, dan menggunakan desain case control, dimana kelompok kasus dibandingkan dengan kelompok kontrol berdasarkan status paparan. Pendekatan yang digunakan adalah retrospektif, dengan meneliti kejadian asfiksia neonatorum dan menganalisis ke belakang variabel - variabel yang dapat mempengaruhi asfiksia neonatorum pada ibu preeklampsia berat seperti riwayat hipertensi dan paritas. 
Penelitian ini dilaksanakan pada bulan Mei 2015 di RSUD Panembahan Senopati Bantul. Sampel kasus diambil dari bayi yang mengalami asfiksia dari ibu dengan preeklampsia berat, sedangkan sampel kontrol diambil dari bayi yang tidak mengalami asfiksia dari ibu dengan preeklampsia berat. Menurut Hair, et al (2006), pada analisis regresi penelitian multivariabel, jumlah subjek penelitian yang disarankan adalah $15-20$ per variabel independen. Pada penelitian ini terdapat dua variabel independen jadi sampel pada penelitian ini yaitu sebanyak 20 x 2 variabel yaitu 40 subjek penelitian, sehingga jumlah subjek penelitian untuk sampel kasus dan kontrol masing - masing adalah 40 subjek penelitian.

Alat dan metode pengumpulan data yang digunakan adalah kajian dokumen pada register ibu bersalin dengan preeklampsia berat di RSUD Panembahan Senopati Bantul selama tahun 2014. Alat yang untuk mengumpulkan data tersebut berupa tabel bantu. Metode pengumpulan data dengan mencatat nomor rekam medis ibu bersalin preeklampsia berat yang bayinya mengalami asfiksia dan tidak asfiksia pada tahun 2014, dengan menentukan populasi dan sampel kemudian melihat status pasien di bagian rekam medik dalam pedoman lembar observasi yang meliputi data ibu: riwayat hipertensi, paritas, data bayi: asfiksia/ tidak asfiksia. Pengolahan data dengan editing, coding, transfering, dan tabulating. Analisis data bivariat dengan uji Chi-Square, dan analisis multivariat dengan regresi logistik ganda.

\section{HASIL DAN PEMBAHASAN}

Karakteristik subjek penelitian yaitu riwayat hipertensi, paritas, umur ibu, dan tingkat pendidikan. Daftar karakteristik subjek penelitian disajikan dalam data kontinu dan kategorik pada tabel berikut ini:
Tabel 1. Data Kontinu Subjek Penelitian

\begin{tabular}{lllllll}
\hline Variabel & & & Mean & $\begin{array}{l}\text { Standar } \\
\text { Deviasi }\end{array}$ & $\begin{array}{l}\text { Mini- } \\
\text { mum }\end{array}$ & $\begin{array}{l}\text { Maksi } \\
\text { mum }\end{array}$ \\
& & & & & \\
\hline $\begin{array}{l}\text { Paritas } \\
\text { Umur ibu }\end{array}$ & 80 & 2 & 29.61 & 6.849 & 1 & 4 \\
(th) & & & & & & \\
\hline
\end{tabular}

Sumber: Data Primer, 2015

Tabel 1. menunjukkan standar deviasi variabel paritas $=0.849$ yang berarti paritas masing - masing subjek penelitian tidak jauh berbeda karena didapatkan nilai mean $=2$, dengan batas minimum $=1$ dan maksimum $=$ 4. Sementara itu, pada variabel umur ibu menunjukkan standar deviasi $=6.534$ yang berarti umur masing - masing ibu jauh dari nilai mean $=29.61$, dengan batas minimum 16 dan maksimum 45 .

Tabel 2. Data Kategorik Subjek Penelitian

\begin{tabular}{lcc}
\hline Variabel & $\mathrm{N}$ & $\%$ \\
\hline Riwayat hipertensi & & \\
Ya & 13 & 16.25 \\
Tidak & 67 & 83.75 \\
Paritas & & \\
$\quad$ Primipara & 38 & 47.5 \\
$\quad$ Multipara & 42 & 52.5 \\
Umur ibu & & \\
$\quad<20, \geq 35$ & 18 & 22.5 \\
$\quad$ berisiko) & 62 & 77.5 \\
20-34 (tidak & & \\
berisiko) & & \\
Tingkat Pendidikan & 31 & 38.75 \\
SD - SMP & 49 & 61.25 \\
SMA - PT & & \\
\hline
\end{tabular}

Sumber: Data Primer, 2015

Tabel 2. menunjukkan hasil bahwa subjek penelitian mayoritas tidak ada riwayat hipertensi (83.75\%), multipara (52.5\%), berumur $20-34$ tahun $(77.5 \%)$, dan berpendidikan SMA - PT (61.25\%). Persentase tersebut tidak selalu mempengaruhi hasil analisis baik bivariat maupun multivariat, karena hanya sebatas mengetahui masing- 
masing persentase pada karakteristik subjek penelitian.

Tabel 3. Tabulasi Silang antara Variabel Independen dengan Dependen

\begin{tabular}{|c|c|c|}
\hline \multirow{4}{*}{ Variabel } & Asfiksia & \multirow{3}{*}{$\begin{array}{c}\mathrm{OR} \\
\mathrm{p}\end{array}$} \\
\hline & Neonatorum & \\
\hline & Ya (\%)Tidak (\%) & \\
\hline & Total $(\%)$ & \\
\hline
\end{tabular}

\begin{tabular}{lcccl}
\hline Riwayat & & & & \\
hipertensi & & & & \\
Ya & 84. & 15. & 100 & 7.21 \\
$\quad$ Tidak & 6 & 4 & 100 & 0.013 \\
Paritas & 43. & 56. & & \\
& 3 & 7 & 100 & \\
Primipara & & & 100 & 2.79 \\
& 63. & 36. & & 0.043 \\
Multipara & 2 & 8 & & \\
Umur Ibu & 38. & 61. & 100 & \\
$\quad<20$, & 1 & 9 & & 1.00 \\
$\geq 35$ & & & 100 & 1.000 \\
20- & 50. & 50. & & \\
34 & 0 & 0 & & \\
Tingkat & 50. & 50. & 100 & \\
Pendidik & 0 & 0 & 100 & 1.70 \\
an & & & & 0.359 \\
$\quad$ SD - & & & & \\
SMP & 41. & 58. & & \\
SMA - & 9 & 1 & & \\
PT & 55. & 44. & & \\
& 1 & 9 & & \\
\hline
\end{tabular}

Sumber: Data Primer, 2015

Tabel 3. menunjukkan hasil analisis Chi - Square pada variabel independen yang mempengaruhi kejadian asfiksia neonatorum sementara adalah pada ibu dengan riwayat hipertensi yang memiliki risiko untuk melahirkan bayi asfiksia paling tinggi yaitu 7.21 kali lebih besar daripada tanpa riwayat hipertensi, sementara ibu primipara memiliki risiko untuk melahirkan bayi asfiksia sebesar 2.79 kali lebih besar daripada multipara, sedangkan faktor yang paling tidak mempengaruhi secara statistik untuk melahirkan bayi asfiksia adalah umur ibu dan tingkat pendidikan. Hasil tersebut masih bersifat sementara, sehingga dilakukan analisis multivariate untuk mengetahui hasil yang lebih signifikan secara statistik.

Tabel 4. Hasil Analisis Multivariat

\begin{tabular}{|c|c|c|c|c|}
\hline \multirow[b]{2}{*}{$\begin{array}{c}\text { Variabel } \\
\text { independen }\end{array}$} & \multirow[b]{2}{*}{ OR } & \multicolumn{2}{|c|}{ CI $95 \%$} & \\
\hline & & $\begin{array}{l}\text { Batas } \\
\text { p } \\
\text { bawah }\end{array}$ & $\begin{array}{l}\text { Batas } \\
\text { atas }\end{array}$ & \\
\hline $\begin{array}{l}\text { Ada riwayat } \\
\text { hipertensi }\end{array}$ & 11.9 & 1.92 & '73.79 & 0.008 \\
\hline Primipara & 3.43 & 1.03 & 10.71 & 0.044 \\
\hline Umur & 0.52 & 0.13 & 2.14 & 0.367 \\
\hline$<20, \geq 35$ & 1.34 & 0.43 & 4.18 & 0.610 \\
\hline SMA-PT & & & & \\
\hline & $=80$ & & & \\
\hline n observasi & $=82.6$ & & & \\
\hline$-2 \log$ & $=39.7$ & & & \\
\hline likelihood & $\%$ & & & \\
\hline Nagelkerke R & & & & \\
\hline Square & & & & \\
\hline
\end{tabular}

Sumber: Data Primer, 2015

Tabel 4 menunjukkan hasil uji analisis regresi logistik ganda tentang riwayat hipertensi, paritas, umur kehamilan, status gizi hubungannya dengan asfiksia neonatorum pada ibu bersalin preeklampsia berat. Terdapat hubungan yang positif dan secara statistik signifikan antara riwayat hipertensi dan paritas dengan risiko untuk melahirkan bayi dengan asfiksia. Ibu dengan riwayat hipertensi memiliki risiko 11.9 kali lebih besar daripada tanpa riwayat hipertensi $(\mathrm{OR}=11.9$; CI 95\% $=$ 1.92 hingga $73.79 ; p=0.008)$. Ibu primipara memiliki risiko untuk melahirkan bayi dengan asfiksia 3.43 kali lebih besar daripada multipara $(\mathrm{OR}=3.43$; CI $95 \%=1.08$ hingga 10.88; $\mathrm{p}=0.036)$. Sementara itu, tidak ada hubungan yang secara statistik signifikan antara umur ibu dan risiko untuk melahirkan bayi asfiksia $(\mathrm{OR}=0.52 ; \mathrm{CI} 95 \%=0.13$ hingga $2.14 ; p=0.367)$. Tidak ada hubungan 
yang secara statistik signifikan antara tingkat pendidikan ibu dan risiko untuk melahirkan bayi asfiksia $(\mathrm{OR}=1,34 ; \mathrm{CI} 95 \%=0.43$ hingga 4.18; $\mathrm{p}=0.610)$. Nilai Nagelkerke $\mathrm{R}$ Square sebesar $39.7 \%$ berarti variabel independen tersebut mempunyai pengaruh sebesar $40 \%$, dan $60 \%$ sisanya merupakan pengaruh untuk terjadinya asfiksia neonatorum pada ibu preeklampsia berat.

Riwayat hipertensi dan primipara, merupakan faktor yang dapat mempengaruhi kejadian asfiksia neonatorum pada ibu bersalin dengan preeklampsia berat. Analisis dengan regresi logistik ganda terhadap variabel bebas dan terikat yaitu didapatkan nilai signifikansi atau peran kebetulan riwayat hipertensi 0,008 , paritas 0,036. Seluruh variabel bebas signifikan berpengaruh terhadap kejadian asfiksia neonatorum karena masing - masing variabel tersebut memiliki nilai signifikansi yang lebih kecil dari 0,05.

Besarnya pengaruh ditunjukkan dengan nilai $\operatorname{Exp}(\mathrm{B})$ atau disebut juga Odds Ratio (OR), didapatkan hasil analisis pada riwayat hipertensi dengan kejadian asfiksia neonatorum $\mathrm{OR}=11,9$, dan paritas dengan kejadian asfiksia neonatorum $\mathrm{OR}=3,43$. Dari hasil penelitian menunjukkan bahwa riwayat hipertensi memiliki nilai OR paling besar yaitu 11.9, berarti ibu preeklampsia dengan riwayat hipertensi merupakan faktor risiko yang paling besar dapat meningkatkan kejadian asfiksia neonatorum.

Hasil penelitian ini di dukung oleh penelitian Kashanian, et al (2011), yaitu ibu dengan riwayat hipertensi tiga kali lebih besar untuk mengalami preeklampsia daripada tanpa riwayat hipertensi $(\mathrm{OR}=2.6)$. Penelitian Jasovic, et al (2015), menyatakan bahwa primipara secara statistik signifikan untuk terjadi preeklampsia daripada multipara ( $\mathrm{p}$ 0.05) dan preeklampsia juga terjadi pada grandemultipara. Hasil penelitian ini juga di dukung oleh penelitian Aabbidha, et al (2011), dengan hasil ibu preeklampsia primipara dan anemia, dapat meningkatkan komplikasi dan kematian baik pada ibu maupun bayi. Komplikasi pada bayi yang terjadi meliputi lahir prematur, BBLR, dan IUFD. Penelitian serupa yang mendukung yaitu penelitian Herianto, dkk (2012), menunjukkan hasil bahwa paritas, riwayat hipertensi, dan anemia terdapat hubungan yang signifikan dengan asfiksia neonatorum.

Menurut Ali, et al (2011), secara teori peningkatan tekanan darah dapat menyebabkan peningkatan hematokrit, dimana terjadi keadaan hemokonsentrasi karena terjadi peningkatan filtrasi plasma transkapiler. Penurunan volume plasma yang menginduksi peningkatan konsentrasi hemoglobin dapat menurunkan sirkulasi plasenta yang memainkan peran patogenik dalam terjadinya preeklampsia. Hubungan antara hemoglobin dan hematokrit pada kehamilan, hasil dari studi kohort menunjukkan bahwa kadar hemoglobin dan hematokrit yang tinggi pada trimester ke-2 memiliki hubungan dengan terjadinya preeklampsia. Sehingga ibu preeklampsia berat dengan anemia dapat melahirkan bayi dalam keadaan asfiksia.

Menurut Prawirohardjo (2008), riwayat hipertensi dan paritas merupakan faktor faktor yang dapat menyebabkan preeklampsia pada ibu hamil. Preeklampsia pada ibu hamil dapat menimbulkan berbagai akibat buruk baik bagi ibu maupun janin. Akibat bagi janin yaitu prematuritas, dismaturitas, IUGR, Asfiksia, BBLR, dan IUFD.

Hasil penelitian ini menunjukkan subjek penelitian yang mengalami preeklampsia berat dan melahirkan bayi asfiksia mayoritas pada usia tidak berisiko (20 - 34 tahun), karena usia 20 - 34 tahun adalah usia reproduktif yang baik untuk melangsungkan kehamilan, sedangkan pada usia $<20$ dan $\geq 35$ tahun merupakan usia yang berisiko untuk melahirkan. Penelitian ini didukung oleh penelitian Jasovic, et al (2015), yaitu pada karakteristik usia ibu secara statistik 
tidak signifikan $(\mathrm{p}>0.05)$. Hal ini berdasarkan peraturan dalam pasal 7 ayat (1) UU Perkawinan yaitu perkawinan hanya diizinkan jika pria sudah mencapai umur 19 (Sembilan belas) tahun dan pihak wanita sudah mencapai umur 18 (delapan belas) tahun. Oleh karena itu, usia 20 - 34 tahun adalah usia dimana perempuan banyak melangsungkan pernikahan, salah satu tujuan utama menikah yaitu untuk mendapatkan keturunan, sehingga mayoritas usia 20 - 34 tahun perempuan tersebut hamil dan melahirkan.

Penelitian ini juga menunjukkan hubungan yang tidak signifikan secara statistik antara tingkat pendidikan dengan asfiksia neonatorum. Subjek penelitian mayoritas berpendidikan SMA dan PT (55.1\%) melahirkan bayi asfiksia. Penelitian yang serupa dari Kashanian, et al (2011), tingkat pendidikan ibu tidak mempengaruhi kejadian preeklampsia yaitu Pendidikan SD $(\mathrm{OR}=0.6)$; Pendidikan SMP-SMA (OR $=0.4)$; Pendidikan Tinggi $(\mathrm{OR}=0.9)$. Tingkat pendidikan yang rendah tidak menjadikan seseorang mempunyai pengetahuan yang rendah, pendidikan kesehatan dapat dilakukan di sekolah, di rumah sakit, dan lain - lain (Notoatmodjo, 2007).

\section{SIMPULAN}

Berdasarkan hasil pembahasan dapat disimpulkan bahwa terdapat hubungan yang positif dan secara statistik signifikan antara riwayat hipertensi dengan risiko untuk melahirkan bayi dengan asfiksia (OR $=11.9$; CI 95\% = 1.92 hingga 73.79; $\mathrm{p}=0.008$ ). Terdapat hubungan yang positif dan secara statistik signifikan antara paritas dengan risiko untuk melahirkan bayi dengan asfiksia (OR = 3.43; CI 95\% = 1.08 hingga 10.88; $\mathrm{p}=0.036$ ). Kesimpulan dari penelitian ini yaitu terdapat hubungan yang positif dan secara statistik signifikan antara riwayat hipertensi dan paritas dengan risiko untuk melahirkan bayi dengan asfiksia. Variabel yang paling besar dapat meningkatkan terjadinya asfiksia pada ibu preeklampsia berat yaitu riwayat hipertensi.

\section{SARAN}

1. Bagi mahasiswa

Meningkatkan informasi tentang faktor - faktor yang dapat menimbulkan asfiksia neonatorum pada ibu preeklampsia berat, dan digunakan untuk menambah referensi untuk penelitian lebih lanjut dengan metode penelitian yang berbeda mengenai asfiksia neonatorum pada ibu preeklampsia berat.

2. Bagi masyarakat

Menambah sumber informasi yang dapat digunakan sebagai upaya preventif mengenai faktor risiko terjadinya preeklampsia berat pada ibu hamil, sehingga kasus preeklampsia berat dapat terdeteksi dini oleh tenaga kesehatan dan kejadian asfiksia neonatorum dapat menurun.

3. Bagi instansi kesehatan

a. Meningkatkan program dalam pelayanan kesehatan ibu dan anak, memberikan pelatihan - pelatihan seperti asuhan persalinan normal, asuhan persalinan dengan komplikasi dan resusitasi bayi baru lahir, serta memperhatikan sarana dan prasarana pelayanan kesehatan khususnya ibu dan anak, sehingga tenaga kesehatan dapat melaksanakan penanganan ibu bersalin dengan preeklampsia berat dengan tepat dan kejadian asfiksia neonatorum menurun.

b. Tenaga kesehatan dapat memberikan informasi dapat dengan menggunakan leaflet atau poster kepada ibu hamil mengenai tanda bahaya kehamilan dan persalinan khususnya mengenai preeklampsia, sehingga kejadian komplikasi kehamilan dan persalinan dapat ditekan. 
c. Bidan Praktik Mandiri (BPM) segera melakukan rujukan pada pasien dengan hipertensi atau preeklampsia ringan, selanjutnya pada umur kehamilan 37 minggu dilakukan terminasi kehamilan di Rumah Sakit, sehingga angka kesakitan dan kematian maternal neonatal menurun.

\section{DAFTAR RUJUKAN}

Abbidha, P., Cheran, A., Paul, E., Helan, J. 2011. Maternal and Fetal Outcome in Preeclampsia in a Secondary Care Hospital in South India. Journal of Family Medicine and Primary Care. Vol. 4.2: 257.

Ali, A.A., Rayis, D.A., Abdallah, T.M., Elbashir M.I., Adam, I. 2011. Severe Anemia is Associated with a Higher Risk for Preeclampsia and Poor Perinatal Outcomes in Kassala Hospital, Eastern Sudan. BMC Res. Vol. 4:311.

Dinas Kesehatan. 2012. Profil Kesehatan Provinsi DIY 2011. Dinkes DIY.

Gilang. 2011. Faktor - Faktor yang Berhubungan dengan Kejadian Asfiksia Neonatorum (Studi Kasus di RSUD Tugurejo Semarang). FK Universitas Muhammadiyah Semarang. Hair, J.F., Black, B.J., Babin, R.E., Anderson, R.L. 2006. Multivariate Data Analysis, 6 Ed., New Jersey : Prentice Hall.

Jasovic, E., Vladimir, J. 2015. Obstetric History and Risk for Mild and Severe Preeclampsia. EC Gynaecology. Vol.1.1: 73-80.

Kashanian, M., Baradaran, H.R., Bahasadri, S., Alimohammadi, R., 2011. Risk Factors for Preeclampsia: A Study in Tehran, Iran. Archives of Iranian Medicine, Vol. 4: 6.

Kemenkes RI. 2010. Asuhan Persalinan Normal. Jakarta: JPNK-KR.

Koopmans, C.M., Karin., Groen, H. 2011. Prediction of Progression to Severe Disease in Women With Gestational hypertension or mild preeclampsia at term. Management of Gestational
Hypertension and mild Preeclampsia at term. Chapter 6: 99.

Koopmans, C.M., Joost J.Z., Groen, H., 2011. Risk Indicators for eclampsia in Women with Gestational Hypertension or Mild Preeclampsia at Term. Management of Gestational Hypertension and mild Preeclampsia at term. Chapter 7: 117.

Koopmans, C.M., Shakila, T., Shalini, I. 2011. Accuracy of Liver Function Test for Predicting Adverse Maternal and Fetal Outcomes in Preeclamptic women: A Systematic Review. Management of Gestational Hypertension and mild Preeclampsia at term. Chapter 10: 169.

Manuaba, I.B.G. 2010. Ilmu Kebidanan, Penyakit Kandungan dan Keluarga Berencana. Jakarta: EGC.

Mansjoer. 2007. Kapita Selekta Kebidanan. Jakarta: Media Aesculapius FK UI.

Notoatmodjo, S. 2007. Kesehatan Masyarakat: Ilmu dan Kiat. Jakarta: Rineka Cipta.

Wong, L., \& Donna. 2009.Keperawatan Pediatrik. Vol. 1. Edisi 6. Jakarta: 
